\title{
APHAKIC STEREOSCOPIC VISION, WITH A NOTE ON THE SYNOPTOPHORE
}

\author{
BY \\ J. Foster, F.R.C.S. \\ WEST HARTLEPOOL \\ AND \\ AUdREY S. JaCkSON \\ SENIOR ORTHOPTIC ASSISTANT, ROYAL WESTMINSTER \\ OPHTHALMIC HOSPITAL
}

APART from irremediable failure of vision in the first operated eye, the propriety of removing a cataractous lens from the other, is usually decided on the following points.

(1) The condition of the eye itself, whether suitable for operation or not.

(2) The age and activity of the patient, mental and physical. A person of active habit leading a useful life may be suitable at any age, though seldom after seventy-five years of age; the younger of course the better.

(3) Some special demand of the patient's occupation for increased field or perception of depth.

In this class we might include leisured motor-drivers whose left cataract has been removed first, and golfers.

It is essential that the patient should have had stereoscopic vision before the lenses became opaque, and that there should be no obvious lesion of the extra-ocular muscles if any stereoscopic vision is to be expected after operation.

Two such cases have been dealt with here (The Royal Westminminster Ophthalmic Hospital) in the last year. One, a sign-writer, wished the extent of his visual field increased, and the other, a gardener, had difficulty in judging the distances of seedlings when " pricking out." Both were satisfied by removal of the second lens, but unfortunately live at a distance, and could not be tested for inclusion in this series. Although we cannot find a paper where stereoscopic vision has been tested in a series of these cases, or one in which the statement is made, it is occasionally said in conversation by ophthalmologists that stereoscopic vision is not obtained after double lens extraction.

This statement is not unreasonable, as other elements of depth perception e.g., accommodation are lost, one eye is in action alone for a considerable period, and the patients are as a rule old people who readjust themselves but slowly to changes of this sort.

Furthermore, the glasses employed introduce another error. With distance glasses of $+10 \mathrm{D}$. and an interpupillary distance of $60 \mathrm{~mm}$., a patient in converging from 6 metres for which the glasses 
are centred, to $30 \mathrm{~cm}$. (just outside reading distance) is subjected to a prismatic effect equal to 5 prism dioptres of exophoria. This would affect the convergence element of depth perception, but could probably be allowed for by experience.

In order to determine the amount of stereoscopic vision in such cases, the following tests were applied to ten cases of bilateral aphakia.

\section{Tests}

(1) Worth's “Four Light Test."

(2) Maddox Rod.

(3) The Synoptophore.

(1) This test in which complementary colours are used to dissociate the images of four lights, demonstrates imperfect fusion or suppression, by allowing the patient to see a larger or smaller number of lights. In the table it is shown whether the patient could overcome the dissociation voluntarily, or whether a prismatic correction was necessary; thus, 5-4 R/L $3 \Delta$. means that five lights were seen by the patient who was able to fuse them to four, after correction of three prism dioptres of right hyperphoria.

(2) The Maddox rod is an additional test of the amount of heterphoria. Apart from its deterrent effect on fusion, Clements has shown that heterophoria alone can disturb the finer degrees of depth perception.

(3) The synoptophore is, so to speak, "the amblyoscope of Worth with a dashboard." The pictures as interpreted by the patient indicate the degree of binocular vision, the corneal reflections the fixation, false or true, while the readings of the instrument show the amount of ocular imbalance. A slight modification of Worth's original terminology is employed, this is based on and similar to, the terminology demonstrated at the Oxford congress by Miss Maddox.

(1) Simultaneous perception I (S.P.). Where the lion is seen beside the cage.

(2) Simultaneous perception II (S.P. 2). Where the lion is in the cage.

(3) Simultaneous macular perception (S.M.P.). Where the bars are seen over the lion without suppression of either. This condition is rarely, if ever, obtained even in adults, the centre of the picture, as a rule, being an unstable compromise between the lion and the cage.

(4) Fusion (F.). Where the two pictures having an object common to both are joined. Since this can be achieved by two eyes, one of which has a "false" (paramacular fixation), one cannot regard these four stages as being strictly in series in a progress towards stereoscopic vision, although they are generally accepted as 


\begin{tabular}{|c|c|c|c|c|c|c|}
\hline 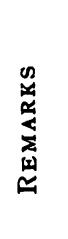 & 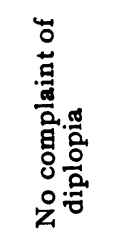 & 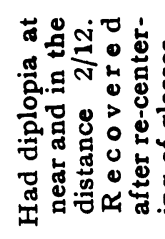 & 1 & 1 & 1 & 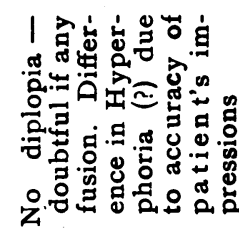 \\
\hline 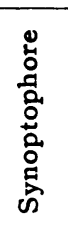 & 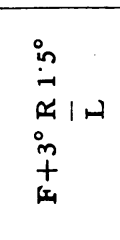 & 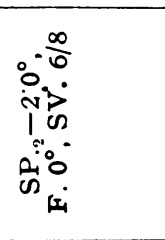 & 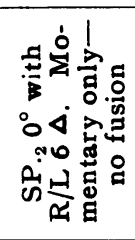 & 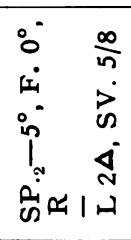 & 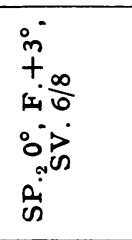 & 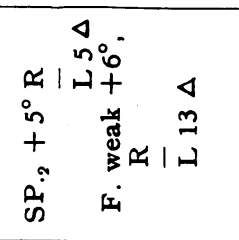 \\
\hline 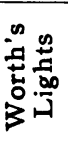 & 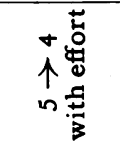 & $\stackrel{+}{+}$ & 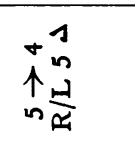 & + & $\begin{array}{l}+ \\
1 \\
\text { in }\end{array}$ & 1 \\
\hline 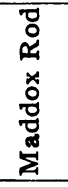 & 1 & 1 & درا شع & 的 & 1 & 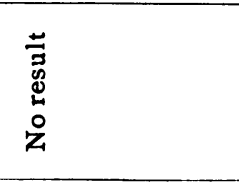 \\
\hline 造 & 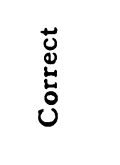 & 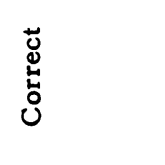 & 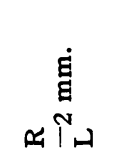 & 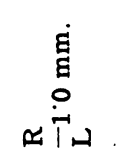 & مُ & 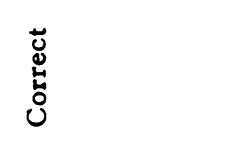 \\
\hline$\vec{\alpha}$ & $\begin{array}{l}\stackrel{0}{0} \\
11 \\
m \\
m \\
+\end{array}$ & 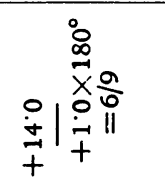 & 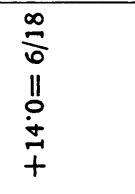 & 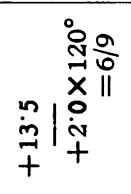 & 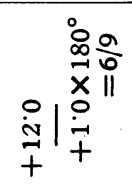 & 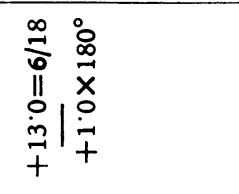 \\
\hline$\vec{i}$ & $\begin{array}{l}\frac{a}{0} \\
11 \\
0 \\
\dot{t} \\
+\end{array}$ & 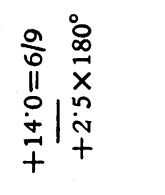 & 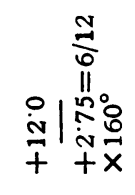 & 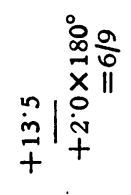 & 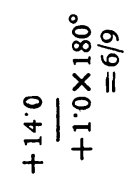 & : \\
\hline 品 & $\vec{m}$ & $\hat{0}$ & 8 & $\stackrel{R}{\circ}$ & $\tilde{N}$ & ก \\
\hline 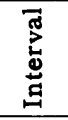 & 苞 n & 9 & $\sigma$ & $\stackrel{\text { N }}{2}$ & t & ळ \\
\hline 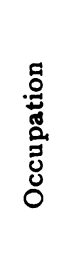 & 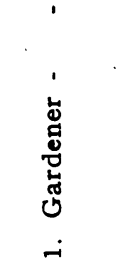 & 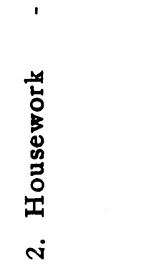 & 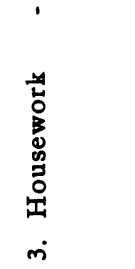 & 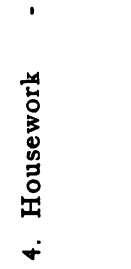 & 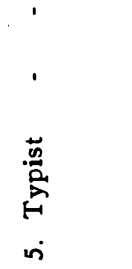 & 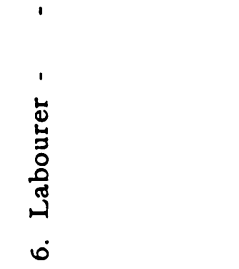 \\
\hline
\end{tabular}


Aphakic Stereoscopic Vision

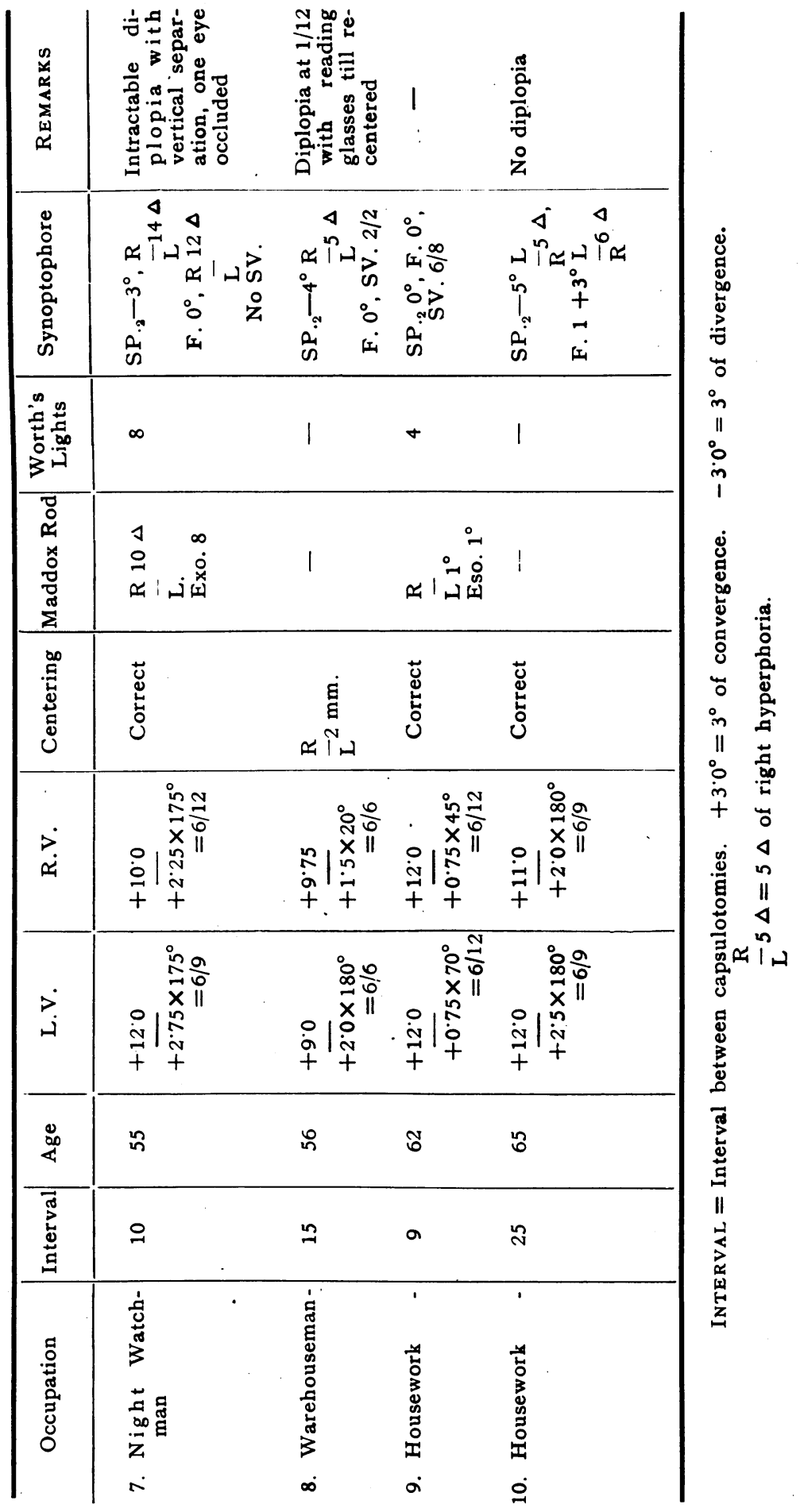


such. In this paper for want of a better classification they are given at their face value. In the table the amount of latent convergence or divergence, and the prismatic correction for hyperphoria are shown thus: $-\mathrm{F} .-3^{\circ} \mathrm{R} / \mathrm{L} 4 \Delta$ means that fusion was achieved with the eyes in a position $3^{\circ}$ of divergence, after 4 prism dioptres of right hyperphoria had been corrected.

(5) Stereoscopic vision proper (S.V.). The acuity of this is tested by the correctness with which the patient locates the position of eight numbers which appear to be at varying distances from the observer. Where the vision is poor the pictures of two larger objects (a hammer and pincers) are employed, and accuracy is expressed as a fraction e.g., $5 / 8$ or $2 / 2$.

As would be expected hyperphoria was the commonest error to interfere with fusion, and in three cases it was directly related to poor centering of the glasses.

No paralysis of extra-ocular muscles was observed in any case. It is sometimes stated that the interval between the operations on the two eyes has a bearing on the degree of stereoscopic vision developed. In this series there appears to be no such relationship. The interval between the restoration of vision to the two eyes is given in months in the table. Another point of interest is that although normal eyes are slightly less convergent as a rule in the tests for fusion than in the tests for simultaneous perception, in these aphakic eyes the opposite condition obtains, although accommodation is necessarily absent.

\section{Results}

Out of ten cases:-

Three, Nos. 2, 5 and 9 had good stereoscopic vision.

Two, Nos. 4 and 8 had good stereoscopic vision with prisms.

Three, Nos. 1, 6 and 10 had fusion with prisms.

One, No. 3 had simultaneous perception with prisms.

One, No. 7 had intractable diplopia.

All these patients were carrying on useful if unaggressive lives, and none except No. 7, who had one eye permanently occluded had the least difficulty in pouring themselves a drink without spilling it.

Simple though this feat sounds, it is quite difficult to perform, after losing the stereoscopic vision on which one has formerly relied, as can be noticed in young workmen who have lost an eye in an accident. It is assumed, of course, that the method employed is not that used by Stagg the blind man in "Barnaby Rudge."

The conclusion would seem to be, that if glasses are fitted with sufficient care, it is worth while removing a second cataract to try and obtain stereoscopic vision, if such would assist a patient in his or her mode of living.

Our thanks are due to the Surgeons of this hospital for permission to publish these cases. 